\title{
Hydrogen-Rich Saline Attenuates Brain Injury Induced by Cardiopulmonary Bypass and Inhibits Microvascular Endothelial Cell Apoptosis Via the PI3K/Akt/GSK3 $\beta$ Signaling Pathway in Rats
}

\author{
Keyan Chen ${ }^{\mathrm{a}} \quad$ Nan Wang ${ }^{\mathrm{b}} \quad$ Yugang Diao $^{c} \quad$ Wanwei Dong $^{\mathrm{a}} \quad$ YingJie Sun ${ }^{\mathrm{c}}$ \\ Lidan Liu ${ }^{d} \quad$ Xiuying $\mathrm{Wu}^{\mathrm{d}}$
}

\begin{abstract}
aDepartment of Laboratory Animal Science, China Medical University, Shenyang, 'The people's Hospital of Liaoning Province, Department of Neurology inspection, the people's Hospital of Liaoning Province, Shenyang, 'Department of Anesthesiology, General Hospital of Shenyang Military Area Command, Shenyang, dDepartment of Anesthesiology, Shengjing Hospital of China Medical University, Shenyang, P.R. China
\end{abstract}

\section{Key Words}

Hydrogen-Rich Saline - Cardiopulmonary Bypass - PI3K/Akt/GSK3 $\beta$ Signaling Pathway • Apoptosis $\cdot$ Inflammation

\begin{abstract}
Background/Aims: Cardiopulmonary bypass (CPB) is prone to inducing brain injury during open heart surgery. A hydrogen-rich solution (HRS) can prevent oxidation and apoptosis, and inhibit inflammation. This study investigated effects of HRS on brain injury induced by CPB and regulatory mechanisms of the PI3K/Akt/GSK3 $\beta$ signaling pathway. Methods: A rat CPB model and an in vitro cell hypoxia model were established. After HRS treatment, Rat behavior was measured using neurological deficit score; Evans blue (EB) was used to assess permeability of the blood-brain barrier (BBB); HE staining was used to observe pathological changes; Inflammatory factors and brain injury markers were detected by ELISA; the PI3K/Akt/GSK3 $\beta$ pathway-related proteins and apoptosis were assessed by western blot, immunohistochemistry and qRT -PCR analyses of brain tissue and neurons. Results: After CPB, brain tissue anatomy was disordered, and cell structure was abnormal. Brain tissue EB content increased. There was an increase in the number of apoptotic cells, an increase in expression of Bax and caspase-3, a decrease in expression of $\mathrm{Bcl} 2$, and increases in levels of Akt, GSK3 $\beta$, P-Akt, and P-GSK3 $\beta$ in brain tissue. HRS treatment attenuated the inflammatory reaction, brain tissue EB content was significantly reduced and significantly decreased expression levels of Bax, caspase-3, Akt, GSK3 $\beta, P-A k t$, and P-GSK3 $\beta$ in the brain. After adding the PI3K signaling pathway inhibitor, LY294002, to rat cerebral microvascular endothelial cells (CMECs), HRS could reduce activated
\end{abstract}

Chen Keyan, PhD,

and Wu Xiuying, PhD
Department of Laboratory Animal Science, China Medical University, and

Department of Anesthesiology, Shengjing Hospital of China Medical University,

Shenyang, (China); E-Mail kychen@cmu.edu.cn,wuxiuying0415@163.com 


\section{Cellular Physiology Cell Physiol Biochem 2017;43:1634-1647 \\ \begin{tabular}{ll|l} 
and Biochemistry & $\begin{array}{l}\text { DOI: 10.1159/000484024 } \\
\text { Published online: October 17, } 2017\end{array}$ & $\begin{array}{l}\text { O 2017 The Author(s). Published by S. Karger AG, Basel } \\
\text { www.karger.com/cpb }\end{array}$ \\
\cline { 49 - 51 }
\end{tabular}}

Akt expression and downstream regulatory gene phosphorylation of GSK3 $\beta$ expression, and inhibit CMEC apoptosis. Conclusion: The PI3K/Akt/GSK3 3 signaling pathway plays an important role in the mechanism of CPB-induced brain injury. HRS can reduce CPB-induced brain injury and inhibit CMEC apoptosis through the PI3K/Akt/GSK3 $\beta$ signaling pathway.

(C) 2017 The Author(s)

Published by S. Karger AG, Basel

\section{Introduction}

Since cardiopulmonary bypass (CPB) has been used in open heart surgery, mortality caused by postoperative myocardial infarction, heart failure, fatal arrhythmia, and other cardiac causes has been significantly reduced [1]. However, recent studies have found that patients often present with cognitive dysfunction, which can manifest as neuropsychiatric and mental disorders [2]. Brain injury after cardiovascular surgery significantly increases the incidence of perioperative complications and associated mortality. It also prolongs ICU retention time and length of hospital stay, thus reducing the patient's quality of life, possibly leading to death, and increasing the mental and economic burden of family members [3, 4]. Therefore, learning how to prevent and treat brain injury induced by CPB surgery has become a great challenge and difficult problem for clinicians.

Apoptosis of nerve cells induced by ischemia and hypoxia in brain tissue is regulated by the phosphatidylinositol kinase-3/serine threonine kinase (PI3K/Akt) pathway [5]. Glycogen synthase kinase-3 $\beta$ (GSK3 $\beta$ ) is a serine/threonine kinase and the major downstream molecule of the PI3K/Akt pathway. The PI3K/Akt/GSK3 $\beta$ signaling pathway mediates cell survival and plays an important role in ischemia-reperfusion injury in the brain, heart, and kidney [6]. GSK3 $\beta$ regulates the cellular endogenous apoptosis pathway, and its downstream molecules include MCL-1 (myeloid lymphoma 1) in the Bcl-2 family [7].

A recent study has shown that a hydrogen-rich solution (HRS), which is generated by dissolving hydrogen into physiological saline solution through special pressurization, is a good antioxidant containing high hydrogen content, weak basicity, negative potential, and small molecule water. It is safe and nontoxic and can balance $\mathrm{pH}$ as well as prevent inflammation, oxidative stress, and apoptosis $[8,9]$. HRS exerts protective effects in the brain, liver, and intestine following ischemia-reperfusion, as well as in myocardial injury. However, the underlying mechanism remains unknown, which limits further development and clinical application [9]. In this study, to investigate effects of HRS on CPB-induced brain injury and the regulatory mechanism of the PI3K/Akt/GSK3 $\beta$ signaling pathway, we established a rat model of CPB, and treated the animals with HRS. Our findings may provide a theoretical basis for understanding mechanisms of perioperative organ injury and developing a protection strategy.

\section{Materials and Methods}

\section{Animals and cells}

Sprague-Dawley rats weighing 350-400 g were obtained from the Experimental Animal Center of China Medical University [production license No. SCXK (Liao)-2013-0001, application license No. SYXK (Liao)-2013-0007]. This study was approved by the China Medical University Laboratory Animal Welfare and Ethics Committee (IACUC N0.2015048R). Rat cerebral microvascular endothelial cells (CMECs) were purchased from Shanghai Kang Lang Technology Co., Ltd.

\section{Sample preparation}

Blood samples of $1 \mathrm{~mL}$ were taken from the internal jugular vein, and the serum was separated by centrifugation at $-80^{\circ} \mathrm{C}$ for ELISA. Rat brain hippocampal tissue was fixed in neutral formalin or stored in liquid nitrogen. 


\section{Cellular Physiology Cell Physiol Biochem 2017;43:1634-1647 and Biochemistry DOI: 10.1159/000484024 2. 2017 舀 2017 The Author(s). Published by S. Karger AG, Basel and Biochemistry \\ Chen et al.: HRS Protect Against Rat Brain Injury by PI3K/Akt/GSK3 $\beta$ Pathway During CPB}

\section{Preparation of hydrogen-rich saline}

Hydrogen-rich saline (HRS) was prepared as previously reported [10]. Briefly, the medical injection bag was subjected to decompression treatment in a low-pressure chamber at 0.8 atmospheric pressure for $24 \mathrm{~h}$, followed by atmospheric pressure for $12 \mathrm{~h}$ for the saturated part of the gas precipitation. The bag was then cooled at $4^{\circ} \mathrm{C}$. Next, $15 \%$ of the total volume was combined with the same volume of pure hydrogen. After injection of salt into the pressurized chamber, the saline was maintained at $4^{\circ} \mathrm{C}$ with continuous pressure for $24 \mathrm{~h}$ to ensure that the hydrogen was fully dissolved. Injection, remove the rear $4^{\circ} \mathrm{C}$ save. HRS prepared in this manner had a concentration of $0.8 \mathrm{mmol} / \mathrm{L}$.

\section{Experimental protocols}

Rats were randomly divided into 3 groups: sham operation (sham group; $\mathrm{n}=10$ ), CPB (CPB group; $\mathrm{n}=10$ ), $C P B+$ HRS (HRS group; $\mathrm{n}=30$ ). In the sham group, intubation and mechanical ventilation were performed, and the right femoral artery and right internal jugular vein were catheterized without bypass. In the CPB group, the CPB model was established as described below. The HRS group was divided into 3 subgroups ( $\mathrm{n}=10$ per subgroup), which were treated with different doses of HRS $(1 \mathrm{~mL} / \mathrm{kg}, 4 \mathrm{~mL} / \mathrm{kg}$, or 6 $\mathrm{mL} / \mathrm{kg})$ via the tail vein. The sham and CPB groups were injected with $0.9 \% \mathrm{NaCl}$ solution $(6 \mathrm{~mL} / \mathrm{kg})$.

CMECs were divided into the following groups: $\mathrm{CPB}$, HRS + CPB (HRS group), PI3K inhibitor + CPB (PI3K group), PI3K inhibitor LY294002 + HRS + CPB (LY group). In the CPB group, CPB was simulated by hypoxia and reoxygenation. HRS was given before hypoxia and during reoxygenation. In the PI3K group, $40 \mu \mathrm{mo1} / \mathrm{L}$ PI3K inhibitor LY294002 was added. In the LY group, both HRS and $40 \mu \mathrm{mo} 1 / \mathrm{L}$ PI3K inhibitor LY294002 were added.

\section{Establishment of the CPB rat model}

CPB was performed as previously reported with minor modifications [11]. Briefly, rats were anesthetized with isoflurane and tracheal intubation was performed using a 16G trocar. A 24G trocar was inserted into the right femoral vein, and a 22G trocar was inserted into the left femoral artery. Another 22G trocar puncture catheter was used as a perfusion artery for extracorporeal circulation. A self-made multihole $18 \mathrm{G}$ puncture needle was placed in the right atrium through a puncture catheter via the right internal jugular vein and served as the extracorporeal venous outflow end. To establish the CPB model, we used the following equipment connected with PVC tubing (internal diameter $=1.6 \mathrm{~mm}$ ): a venous drainage tube, blood reservoir, arterial infusion tube, filter, and connecting pipe. A total of $15 \mathrm{~mL}$ of circulating prefilled solution consisted of $6 \mathrm{~mL}$ hydroxyethyl starch, $6 \mathrm{~mL}$ lactate Ringer's solution, $1 \mathrm{~mL}$ heparin $(250 \mathrm{IU} / \mathrm{kg})$, $5 \%$ sodium bicarbonate, and $1 \mathrm{~mL}$ of $20 \%$ mannitol (Fig. 1A). When CPB began, mechanical ventilation was terminated, and CPB flow rate was more than $80 \mathrm{~mL} / \mathrm{kg} / \mathrm{min}$. Circulation volume was adjusted to ensure the flow rate resulted in a flow time of $60 \mathrm{~min}$. During CPB, an oxygen-air mixture (at a ratio of 1:4) passed through the membrane lung at a rate of $800 \mathrm{~mL} / \mathrm{min}$. Mechanical ventilation was restarted before the flow was reduced, and circulation volume was gradually decreased by adjusting the diameter of the venous outflow end. The right internal jugular vein and caudal artery were ligated, followed by removal of the catheter and suture of the incision. After the rat resumed spontaneous breathing, tracheal intubation was removed, and the rat was fed in the laboratory for observation.

\section{Establishment of the hypoxia-reoxygenation model}

CMECs were subjected to hypoxic conditions to simulate effects of CPB on myocardial cells. The hypoxic solution consisted of $\mathrm{NaCl} 137 \mathrm{mM}, \mathrm{KCl} 12 \mathrm{mM}, \mathrm{MgCl}_{2} 0.49 \mathrm{mM}, \mathrm{CaCl}_{2}-2 \mathrm{H}_{2} \mathrm{O} 0.9 \mathrm{mM}$, HEPES $4 \mathrm{mM}$, deoxyglucose $10 \mathrm{mM}$, sodium sulfite $0.75 \mathrm{mM}$, sodium lactate $20 \mathrm{mM}, \mathrm{pH}$ 6.5. During hypoxia, the cells were placed in $95 \% \mathrm{~N}_{2}$ and $5 \% \mathrm{CO}_{2}$ for $2 \mathrm{~h}$. During reoxygenation, the cells were placed in normal culture medium and transferred to an incubator for $4 \mathrm{~h}$.

\section{Neurological function score}

Neurological function scores of rats in each group were assessed according to the Longa scale [12]. Scoring criteria were as follows: 0 , no obvious neurological deficit; 1 , left limb could flex but not extend when lifting the tail (mild); 2, unilateral circling, animals could maintain balance at a resting state (moderate); 3 , animals were unstable and inclined to the contralateral side at a resting state (severe); 4 , no visible activity (extremely severe). 


\section{Cellular Physiology Cell Physiol Biochem 2017;43:1634-1647 \\ \begin{tabular}{l|l|l} 
DOI: 10.1159/000484024 & $\begin{array}{l}\text { O 2017 The Author(s). Published by S. Karger AG, Basel } \\
\text { www.karger.com/cpb }\end{array}$
\end{tabular} \\ Chen et al.: HRS Protect Against Rat Brain Injury by PI3K/Akt/GSK3 $\beta$ Pathway During CPB}

Evans blue (EB)

EB was used as a tracer to assess permeability of the blood-brain barrier (BBB) according to the Belayev method. Animals in each group were injected with $2 \%$ EB $(20 \mathrm{mg} / \mathrm{kg})$ into the femoral vein. The rats were killed, and the whole brain was removed. The tissue was fixed in $3 \mathrm{~mL}$ of formamide and incubated at $54^{\circ} \mathrm{C}$ for $24 \mathrm{~h}$. Optical density (OD) was measured after mixing the supernatant. BBB permeability is expressed as EB content.

\section{ELISA}

Levels of inflammatory factors, such as IL-1 $\beta$ (SEA563Ra, CCC, USA), IL-6 (SEA079Ra, CCC), TNF- $\alpha$ (SEA133Ra, CCC), and brain injury markers, such as S-100ß (SEA567Ra, CCC) and NSE (SEA537Ra, CCC), in rat plasma were measured using an ELISA kit (USCN, USA). OD at $450 \mathrm{~nm}$ was measured with a microplate reader. A standard curve was generated by plotting OD value versus standard concentration. The curve equation and $r$ value were calculated and used to determine concentrations of samples.

\section{Histological staining}

Brain hippocampal tissue was harvested, fixed with neutral formalin, dehydrated with ethanol, cleared with xylene, and embedded in paraffin. Next, $5 \mu$ m thick sections were cut and stained. After staining, sections were dehydrated, rinsed, and cleared in xylene. Pathological changes of brain tissue were then observed using light microscopy.

\section{Immunohistochemistry}

Immunohistochemistry was performed to localize Akt, GSK3 $\beta$, p-Akt, and p-GSK3 $\beta$. Brain hippocampal tissue was fixed in $4 \%$ paraformaldehyde, embedded in paraffin, sliced at a thickness of about $4 \mu \mathrm{m}$, and then placed in a $58-60^{\circ} \mathrm{C}$ oven for $30-60 \mathrm{~min}$. Slices were dewaxed for $15 \mathrm{~min}$, rinsed with distilled water 3 times, and immersed in $0.01 \mathrm{M}$ citrate buffer ( $\mathrm{pH}$ 6.0). Then, slices were heated to boiling, and the power was turned off every 5-10 min. Next, slices were rinsed once or twice with $0.02 \mathrm{M}$ citrate buffer and then incubated with normal rabbit blocking solution for $20 \mathrm{~min}$ at room temperature. This was followed by incubation with Akt (ab179463, Abcam, USA), p-Akt (ab131443, Abcam), GSK3ß (ab93926, Abcam), or p-GSK3 $\beta$ (ab75745, Abcam) antibodies at $37^{\circ} \mathrm{C}$ for $1 \mathrm{~h}$. The slices were then washed 3 times with $0.02 \mathrm{M}$ PBS ( 2 min per wash). Next, the tissue was incubated with biotinylated goat anti-rabbit IgG at $37^{\circ} \mathrm{C}$ for 20 min, washed 3 times with $0.02 \mathrm{M}$ PBS ( 2 min per wash), incubated with reagent $\mathrm{SABC}$ at $37^{\circ} \mathrm{C}$ for $20 \mathrm{~min}$, and then rinsed 4 times with $0.02 \mathrm{M}$ PBS ( 5 min per wash). Finally, slices were stained with DAB, and observed under a microscope.

\section{TUNEL staining}

Apoptosis of brain hippocampal tissues was assessed using a TUNEL kit (In Situ Cell Death Detection Kit-POD, Roche, 11684817910) according to the manufacturer's instructions. Brain tissue was dehydrated, embedded, sliced, and incubated with $0.9 \% \mathrm{NaCl}$ for $5 \mathrm{~min}$. Next, tissue was rinsed twice with PBS mixed with biotinylated nucleotides and terminal deoxynucleotidyl transferase, covered with plastic coverslips, and incubated at $37^{\circ} \mathrm{C}$ for $60 \mathrm{~min}$. After another PBS wash, tissue was blocked with $0.3 \%$ hydrogen peroxide, Add $50 \mu$ of TUNEL reaction mixture, Incubate for $60 \mathrm{~min}$ at $37^{\circ} \mathrm{C}$ in a humidified atmosphere in the dark. Rinse slide(s) three times in PBS for 5 min each.Samples can be analyzed in a drop of PBS under a fluorescence microscope at this state.

\section{MTT colorimetry}

Cells in the logarithmic growth phase were inoculated into 96-well culture plates at a density of 20005000 per well and $100 \mu \mathrm{L}$ cells per well. Next, $20 \mu \mathrm{L}$ MTT solution $(5 \mathrm{mg} / \mathrm{mL})$ was added to each well, and cells were cultured for another $4 \mathrm{~h}$. The supernatant was removed and $150 \mu \mathrm{L}$ DMSO was added per well. Cells were shaken for $10 \mathrm{~min}$, and the crystals were fully dissolved. OD at $570 \mathrm{~nm}$ was measured with microplate reader, and cell survival and inhibition rates were calculated as follows: cell survival rate $=$ (OD value of the treatment group/OD value of the normal control group) $\times 100$, inhibition rate $=1-$ OD value of the treatment group/OD value of the control group.

\section{KARGER}




\section{Cellular Physiology Cell Physiol Biochem 2017;43:1634-1647 \begin{tabular}{ll|l} 
DOI: 10.1159/000484024 & $\begin{array}{l}\text { O } 2017 \text { The Author(s). Published by S. Karger AG, Basel } \\
\text { www.karger.com/cpb }\end{array}$ \\
\hline and Biochemistry
\end{tabular}

\section{Flow cytometry}

The Annexin V-PI (556547, BD, USA) method was used to measure the apoptosis rate of CMECs by flow cytometry. Cells were harvested with $0.05 \%$ trypsin, washed 3 times with cold PBS $\left(4^{\circ} \mathrm{C}\right)$, and collected by centrifugation at $1000 \mathrm{rpm}$ for $5 \mathrm{~min}$. Next, cells were resuspended in $200 \mu \mathrm{L}$ binding buffer and incubated with Annexin V $(10 \mu \mathrm{g} / \mathrm{mL})$ and PI $(10 \mu \mathrm{g} / \mathrm{mL})$ in the dark for $15 \mathrm{~min}$ at room temperature. Then, cells were analyzed using a flow cytometer (BD).

\section{Western blot analysis}

Samples were lysed in complete RIPA buffer (89900, Thermo, USA). Protein concentration of tissue homogenates was measured using the Bio-Rad protein assay (Bio-Rad, Hercules, CA, USA). Equal amounts of soluble protein were separated on $10 \%$ polyacrylamide gels and transferred to nitrocellulose membranes. Each nitrocellulose membrane was blocked $2 \mathrm{~h}$ and incubated overnight at $4^{\circ} \mathrm{C}$ with $\mathrm{Bcl}-2$ (ab59348, Abcam), Bax (ab32503, Abcam), caspase-3 (ab13847, Abcam), Akt (ab179463, Abcam), p-Akt (ab131443, Abcam), GSK3 $\beta$ (ab93926, Abcam), or p-GSK3 $\beta$ (ab75745, Abcam) antibodies. This was followed by 3 washes and incubation with secondary antibody for $1 \mathrm{~h}$. After 4 washes with TBST, signals were visualized using an ECL luminescence kit and a gel imaging system. Band densities were measured using Quantity One software (Bio-Rad).

\section{Quantitative real-time PCR}

Primers were designed according to the sequences of $\mathrm{Bax}, \mathrm{Bcl} 2$, and caspase 3 reported in Genbank and were synthesized by the Shanghai Biomedical Biotechnology Co., Ltd. Total RNA was isolated with TRIzol reagent (15596018, Invitrogen) and reverse transcribed into cDNA (4387406, Invitrogen). A real-time PCR kit (RR820A, TAKARA, China) was used to measure expression levels. The relative gene expression data was analyzed with the $2^{\wedge}$ (-Delta Delta CT) method. The primers used for real-time PCR were as follows:

Bax-F: GTGGATACAG ACTCCCCC

Bax-R: AGCGGCTGTT TGTCTGGA

Bcl2-F: TGATAACCGG GAGATCGTGA

Bcl2-R: TCTCTGAAGA CGCTGCTCAG

Caspase 3-F: TGAATGGAAA CAACCAGT

Caspase 3-R: TCAAGCACCT GACCCTTA

GAPDH-F: AACTTTGGCATTGTGGAAGG

GAPDH-R: CACATTGGGGGTAGGAACAC

\section{Statistical analysis}

Data were analyzed using SPSS 19.0 statistical software, and measurement data are expressed as mean \pm standard deviation. Comparisons between groups were made using the Student's $t$ test (2-tailed) or ANOVA with Tukey's post-test analysis. A value of $\mathrm{P}<0.05$ was regarded as a significant difference.

\section{Results}

\section{Establishment of the CPB model in rats}

All rats were awake 60-90 minutes after anesthesia. Rats in the sham group did not show obvious neurological deficits. Rats in the CPB group showed different degrees of neurological abnormalities. Compared with the sham group, neurological deficit scores significantly increased after CPB (P < 0.05) as shown in Fig. 1B. In the CPB group, rectal temperature, $\mathrm{pH}$, and arterial blood partial pressure of carbon dioxide $\left(\mathrm{PaCO}_{2}\right)$ were stable, but partial pressure of oxygen $\left(\mathrm{PaO}_{2}\right)$ and hemoglobin decreased (Fig. 1C).

\section{Different concentrations of HRS attenuated brain tissue injury after CPB}

In determining the optimal concentration of HRS treatment in CPB, we observed that in the sham group, the hippocampus showed normal morphology with clear boundaries and complete cell bands; no abnormal cell structures were found with HE staining (Fig. 2A). In addition, we did not observe significant neurological deficits (Fig. 2B). In the CBP group, 
cells were tightly arranged, and cell bands were not complete (Fig. 2A). Rats had difficulty maintaining balance in a quiet state (Fig. 2B). Brain tissue EB content increased after CPB; however, after HRS $6 \mathrm{~mL} / \mathrm{kg}$ treatment, brain tissue EB content was significantly reduced $(\mathrm{P}<$ 0.05) (Fig 2C). After CPB, inflammatory factors and brain injury markers were significantly increased (Fig. 2D,E). In contrast, after HRS $6 \mathrm{~mL} / \mathrm{kg}$ treatment, neurons showed normal morphology (Fig. 2A-E), every limb extended freely, and inflammatory factors and brain injury markers decreased (Fig 2D,E). These data indicate that 6 $\mathrm{mL} / \mathrm{kg}$ HRS significantly attenuated brain tissue injury after CPB.

\section{HRS protected brain} hippocampal tissue from $\quad C P B$-induced apoptosis

In analyzing effects of HRS on apoptosis in $\mathrm{CPB}$, we observed that the number of TUNEL-positive cells significantly increased in the CPB group, whereas the number of apoptotic cells decreased after HRS treatment (Fig. 3A). Next, we examined apoptosisrelated proteins and mRNA expression. In the CPB group, expression levels of Bax and caspase- 3 in brain tissue were markedly higher, while Bcl-2 expression was significantly lower. After HRS treatment, Bax

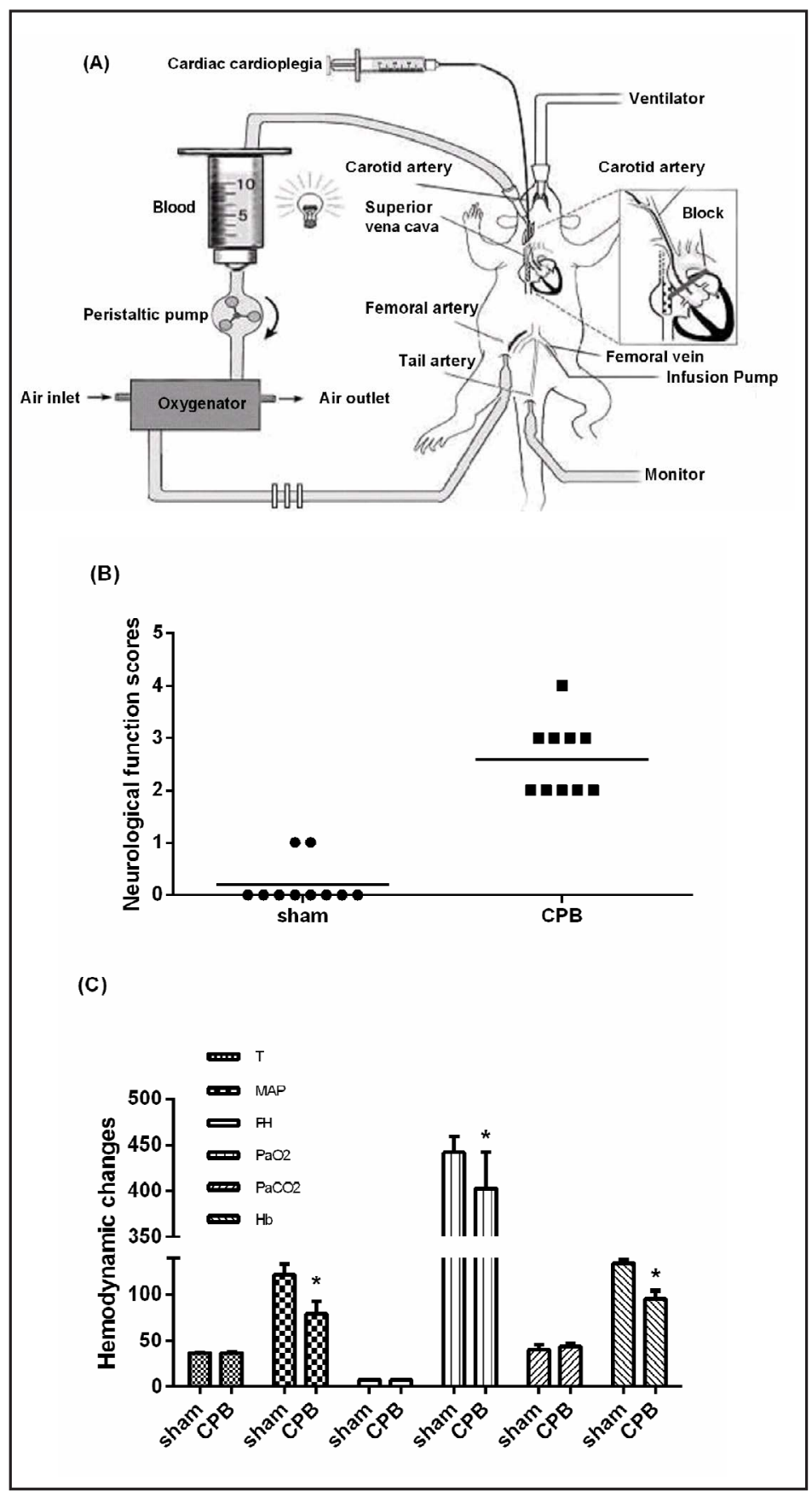

Fig. 1. $\mathrm{CPB}$ model in rats. The rat $\mathrm{CPB}$ model was established, and $24 \mathrm{~h}$ later the rats were evaluated for neurological function scores. Hemodynamic parameters were observed in rats after CPB. A: CPB rat model. B: Comparison of neurological function scores of rats in the sham and CPB groups. C: Hemodynamic parameters after CPB. Temperature, $\mathrm{pH}$, and $\mathrm{PaCO}_{2}$ were stable, but $\mathrm{PaO}_{2}$ and hemoglobin decreased. Compared with the sham group, ${ }^{*} \mathrm{P}<0.05$. and caspase-3 expression decreased, while Bcl-2 expression increased (Fig. 3B-D). These results suggest that CPB could cause neuronal apoptosis and that HRS protected brain tissue from CPB. 
(A)

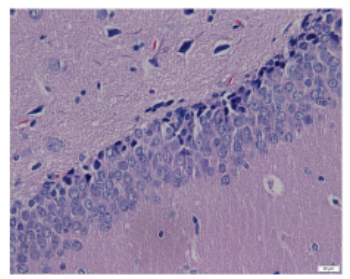

Sham

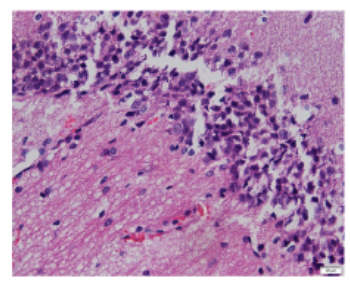

CPB

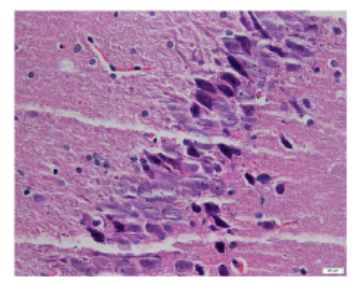

HRS $1 \mathrm{ml} / \mathrm{kg}$

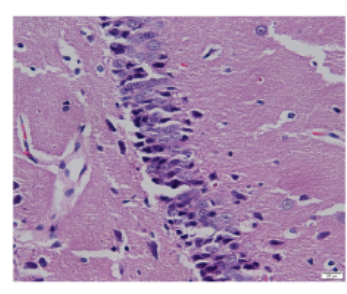

HRS $4 \mathrm{ml} / \mathrm{kg}$

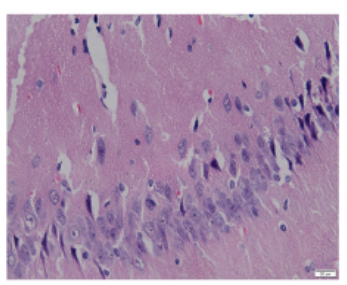

HRS $6 \mathrm{ml} / \mathrm{kg}$

(B)

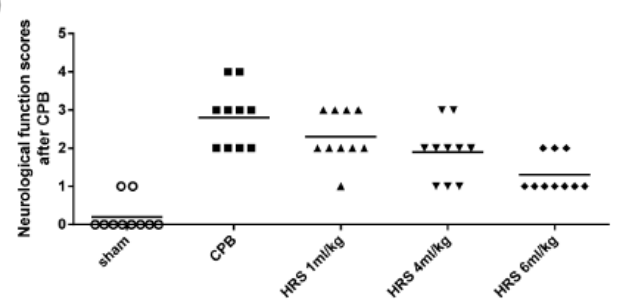

(D)

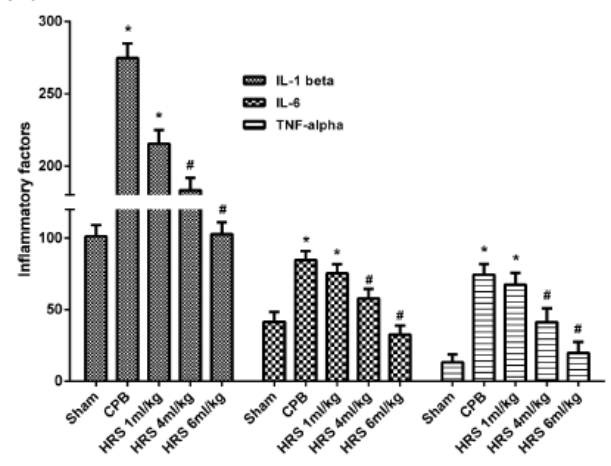

(C)
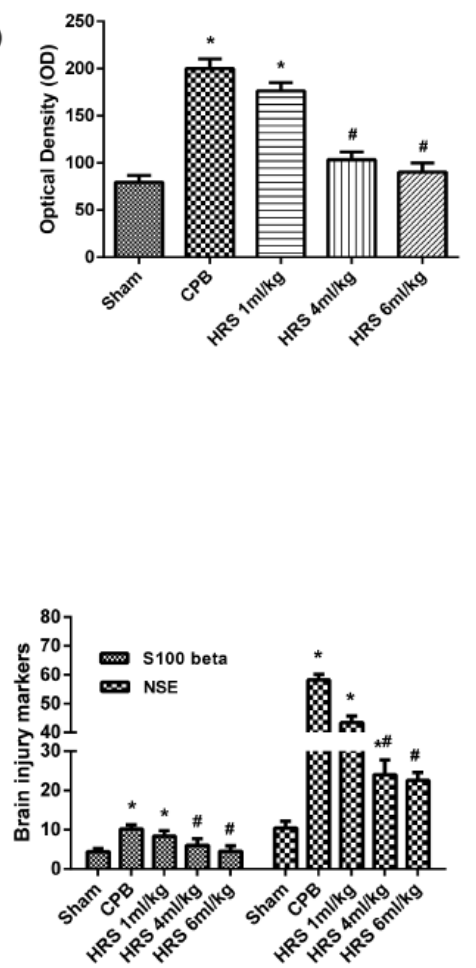

Fig. 2. Different concentrations of HRS attenuated brain tissue injury after CPB. After establishment of the rat CPB model, animals were treated with $1 \mathrm{~mL} / \mathrm{kg}, 4 \mathrm{~mL} / \mathrm{kg}$, or $6 \mathrm{~mL} / \mathrm{kg}$ of HRS. At $24 \mathrm{~h}$ after CPB, the hippocampus was stained with HE to assess pathological changes. In addition, neurological function scores were determined, BBB permeability was measured using Evans Blue, and changes in levels of inflammatory factors and brain injury markers in serum were detected by ELISA. These data indicate that $6 \mathrm{~mL} / \mathrm{kg} \mathrm{HRS}$ significantly attenuated brain tissue injury after CPB. A: HE staining. B: Comparison of neurological function scores of rats in each group. C: Inflammatory factor (IL-1 $\beta$, IL-6, TNF- $\alpha$ ) expression levels measured by ELISA. D: Brain injury marker (S-100 $\beta$, NSE) expression levels measured by ELISA.Compared with the sham group, ${ }^{*} \mathrm{P}<0.05$. Compared with the $\mathrm{CPB}$ group, $\# \mathrm{P}<0.05$. 


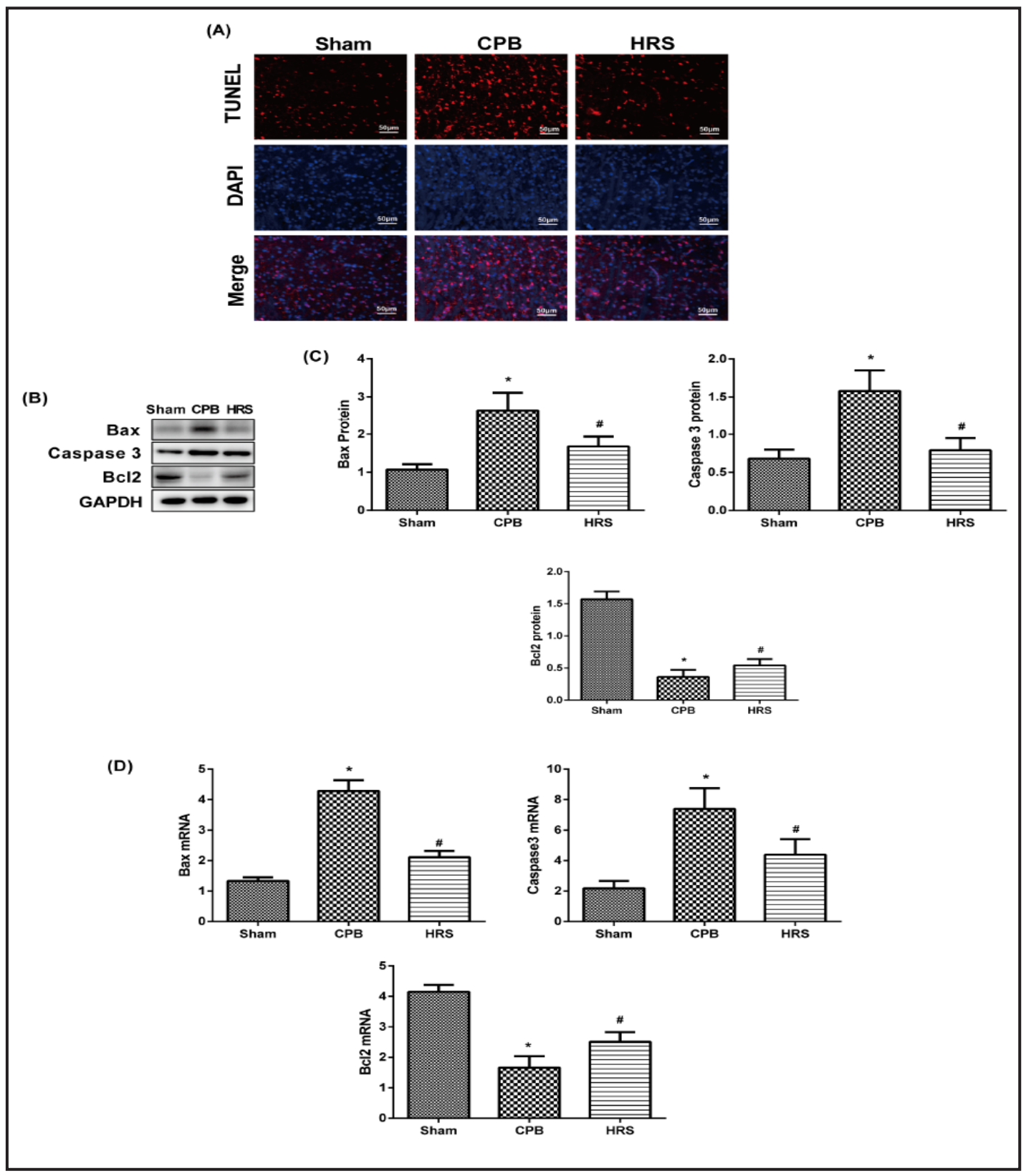

Fig. 3. HRS protected brain tissue from CPB-induced apoptosis. After establishment of the CPB model in rats, animals were treated with $6 \mathrm{~mL} / \mathrm{kg}$ HRS. TUNEL staining was used to detect apoptotic cells in brain hippocampal tissue. Western Blot and real-time quantitative PCR were used to assess expression of Bax, Bcl2, and caspase- 3 in the hippocampus. Data were collected from the sham, CPB, and HRS treatment groups. A: Apoptotic cells detected by TUNEL staining.B-C: Western blot analysis and quantitative real-time PCR of Bax, caspase- 3 , and Bcl2. Compared with the sham group, ${ }^{*} \mathrm{P}<0.05$. Compared with the CPB group, $\# \mathrm{P}<0.05$.

HRS inhibited neuronal apoptosis via the PI3K/Akt/GSK3 $\beta$ signaling pathway after CPB in rats

To confirm whether the PI3K/Akt/GSK3 $\beta$ signaling pathway mediates neuronal apoptosis, we assessed expression levels of several key factors in the signaling pathway. In the CPB group, expression of Akt, GSK3 $\beta$, P-Akt, and P-GSK3 $\beta$ increased. However, after 


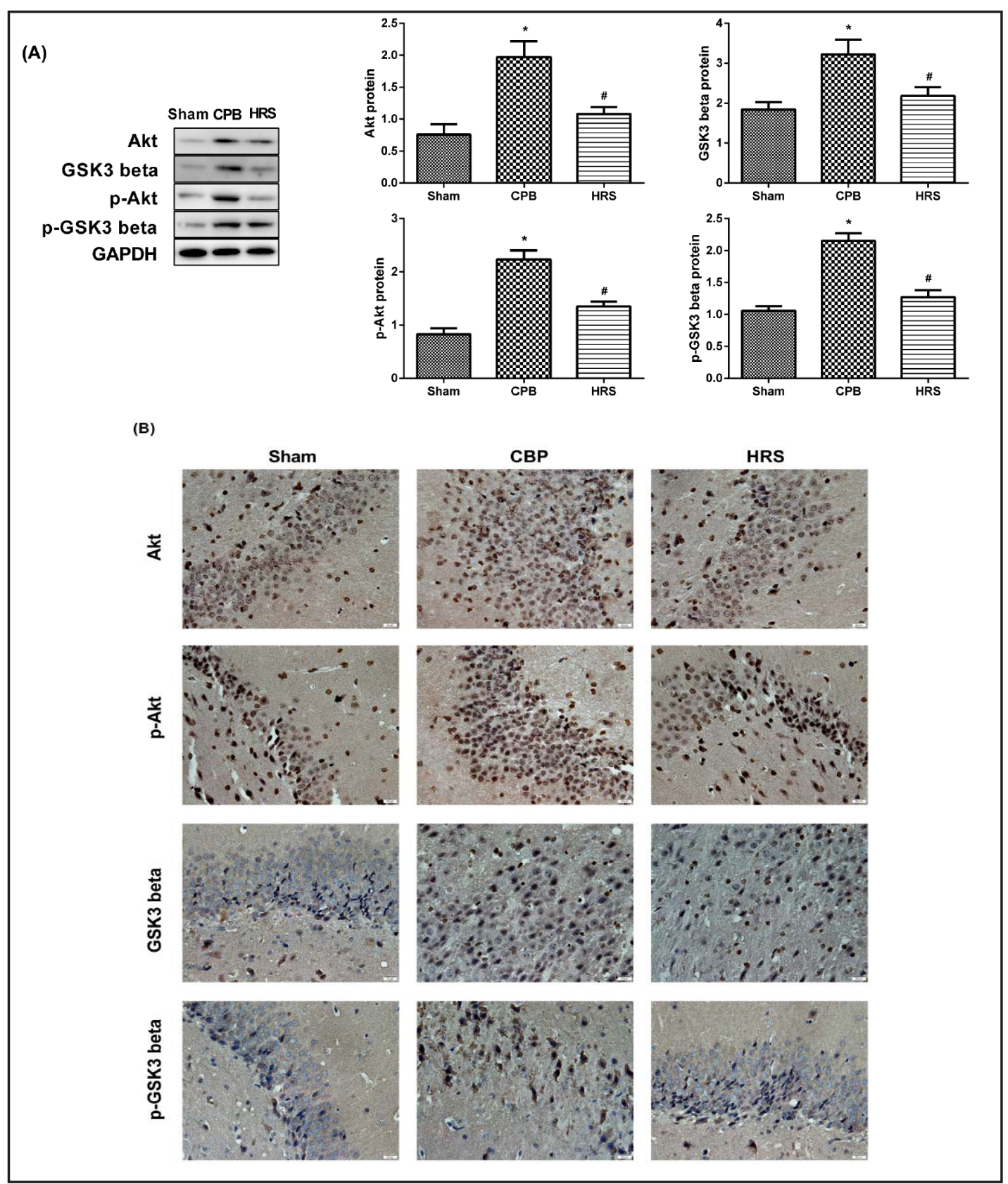

Fig. 4. HRS inhibited neuronal apoptosis via the PI3K/Akt/GSK3 $\beta$ signaling pathway after CPB in rats. After establishment of the CPB model in rats, animals were treated with $6 \mathrm{~mL} / \mathrm{kg}$ HRS. Expression of pathwayassociated proteins Akt, GSK3 $\beta, \mathrm{p}$-Akt, and p-GSK3 $\beta$ was assessed by western blotand immunohistochemistry. Data were collected from the sham, CPB, and HRS treatment groups. A: Western blot of Akt, GSK3 $\beta$, p-Akt and p-GSK3 $\beta$. B: Immunohistochemistry of Akt, GSK3 $\beta$, p-Akt, and p-GSK3 $\beta$. Compared with the sham group, $* \mathrm{P}<0.05$. Compared with the CPB group,\# $\mathrm{P}<0.05$.

treatment with HRS, expression of these proteins was closer to normal levels (Fig. 4A). Results from tissue localization were consistent with these findings (Fig. 4B). Our results show that HRS protection against CPB-induced apoptosis may be mediated by the PI3K/Akt/ GSK3 $\beta$ signaling pathway. 
Fig. 5. HRS attenuated effects of hypoxia in CMECs. After establishing the hypoxia/reoxygenation model in CMECs, 40 $\mu \mathrm{mo1} / \mathrm{L}$ of PI3K inhibitor LY294002 was added, and a MTT colorimetric assay was used to assess viability of CMECs. Flow cytometry was used to determine the apoptosis rate of CMECs, and western blot analysis was used to assess expression of apoptosis-related proteins Bax, $\mathrm{Bcl} 2$, and caspase-3. Data were collected from the CPB, HRS, PI3K, and LY groups. A: Survival of CMECs. B-C: Apoptosis rate of CMECs determined by flow cytometry.D: Expression of apoptosis-related proteins. Compared with the CPB group, ${ }^{*} \mathrm{P}<0.05$; Compared with the PI3K group, " $\mathrm{P}<0.05$.
(A)

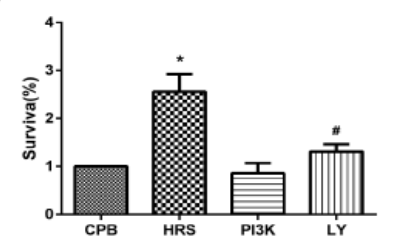

(C)

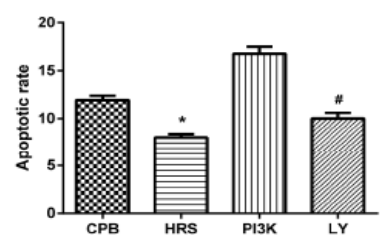

(B)

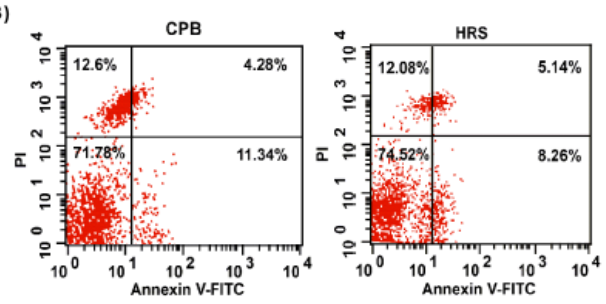

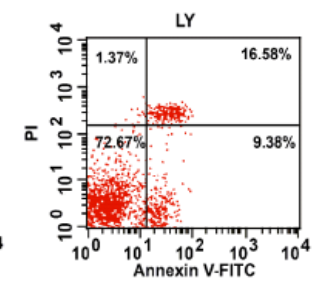

(D)
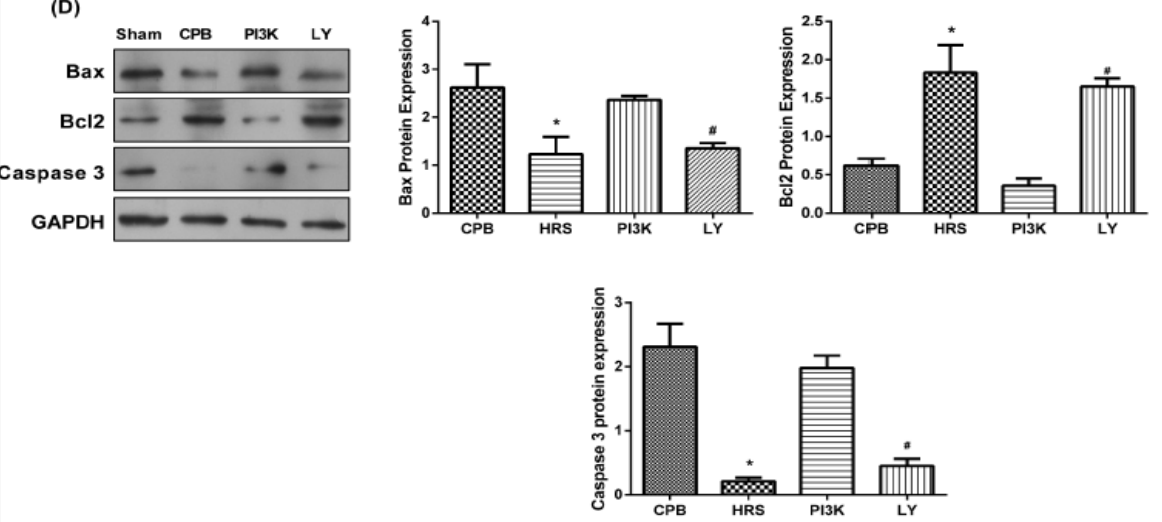

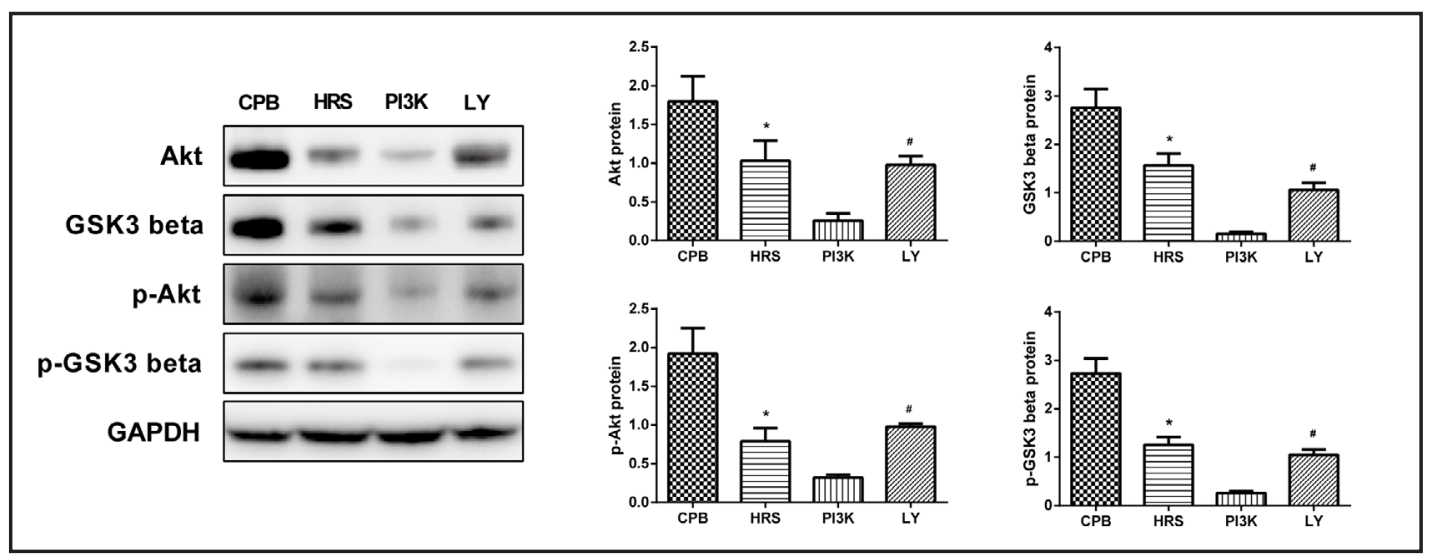

Fig. 6. HRS inhibited apoptosis in CMECs through the PI3K/Akt/GSK3 $\beta$ signaling pathway. We examined the effect of treating CMECs with $40 \mu \mathrm{mo} 1 / \mathrm{L}$ of PI3K inhibitor LY294002 on expression of downstream key proteins Akt, GSK3 $\beta$, p-Akt, and p-GSK3 $\beta$, which was assessed by western blot. Data were collected from the CPB, HRS, PI3K, and LY groups. Compared with the CPB group, ${ }^{*} \mathrm{P}<0.05$; Compared with the PI3K group, ${ }^{\#} \mathrm{P}<0.05$. 
Chen et al.: HRS Protect Against Rat Brain Injury by PI3K/Akt/GSK3 $\beta$ Pathway During CPB

\section{HRS attenuated effects of hypoxia in CMECs}

Cell viability in each group was assessed by MTT assay after reoxygenation. HRS treatment enhanced viability of CMECs after hypoxia/reoxygenation $(\mathrm{P}<0.05)$ (Fig. 5A).

\section{HRS protected CMECs from apoptosis in vitro}

The Annexin V-PI method was used to measure the apoptosis rate of CMECs. As shown in Fig. 5B, HRS treatment significantly reduced the apoptosis rate of CMECs after hypoxia/ reoxygenation $(\mathrm{P}<0.05$ ) (Fig $5 \mathrm{C})$. In addition, western blot analysis showed that Bax and caspase-3 expression decreased, while Bcl-2 protein increased (Fig. 5D). These data indicate that HRS could protect CMCEs from apoptosis.

\section{HRS inhibited apoptosis in CMECs through the PI3K/Akt/GSK3 $\beta$ signaling pathway}

We further investigated the mechanism underlying the anti-apoptosis effect of HRS using LY294002, which is PI3K pathway inhibitor. The data show that after adding the inhibitor and treating CMECs with HRS, activated Akt expression was significantly reduced, and downstream regulatory gene phosphorylation of GSK3 $\beta$ expression was significantly reduced (Fig. 6). These data indicate that HRS could reduce CPB-induced brain injury through the PI3K/Akt/GSK3 $\beta$ signaling pathway.

\section{Discussion}

In this study, we established a rat CPB model to observe effects of HRS on CPB-induced brain injury, pathohistology, apoptosis, and expression levels of Bcl-2, Bax, caspase3, inflammatory factors, and the PI3K/Akt/GSK3 $\beta$ signaling pathway. Results show that HRS can reduce CPB-induced pathological brain tissue changes, lower expression of inflammatory factors, and reduce apoptosis. Furthermore, HRS can protect the brain against CPB-induced brain injury and inhibit Bax, caspase-3, Akt, GSK3 $\beta$, p-Akt, and p-GSK3 $\beta$ expression in the brain. The PI3K/Akt/GSK3 $\beta$ pathway plays a crucial role in apoptosis of CMECs, and HRS inhibits apoptosis through the PI3K/Akt/GSK3 $\beta$ pathway. The incidence of CPB-induced brain injury is increasing annually and has become an urgent problem. This study provides experimental and theoretical evidence for improving perioperative protection of brain tissue during heart surgery.

At present, CPB is the main method of clinical heart surgery. Because CPB devices are continuously being developed and anesthesia techniques and surgical skills are gradually improving, heart surgery complications and mortality have been significantly reduced. However, an increasing number of studies have reported CPB-induced brain injury and related inflammatory responses in which the pathogenesis unclear [4]. A good CPB model is essential for studying therapeutic and prophylactic measures. In the present study, a $\mathrm{CPB}$ model was established by injecting $6 \%$ hydroxyethyl starch into rats through the right venous drainage and right femoral arterial fusion. Our study shows that CPB could cause brain tissue injury, which was characterized by neuronal apoptosis, an increase in brain injury markers, and a significant increase in serum inflammatory factors at $6 \mathrm{~h}$ following the procedure. These findings suggest that $\mathrm{CPB}$ can induce brain neuronal injury and a systemic inflammatory response. Thus, this CPB model may reflect clinical features and be used as experimental tool to study the systemic inflammatory response as well as organ and other related protective mechanisms.

Hydrogen is the most effective natural antioxidant. Thus, HRS has a strong reducing function and can neutralize free radicals within blood and cells [8]. HRS can easily enter cells, become involved in metabolism, and thereby promote cell detoxification, increase cell hydration, and enhance the body's immune system [13, 14]. Li et al. [15] investigated effects of HRS on prevention of renal injury induced by ischemia/reperfusion. The results show that after ischemia/reperfusion injury, levels of BUN, Cr, Bcl-2, caspase-3, caspase-9, caspase-8, IL-6, and TNF- $\alpha$ significantly increased, while Bax expression decreased. HRS remarkably 
reversed these changes. HRS might partially exert its role through an anti-apoptotic and anti-inflammatory action in kidney cells. Gokalp et al [16] found that HRS was protective in attenuating ischemia/reperfusion-induced ovary injury according to histopathological and biochemical examinations. Shi et al. [17]found that HRS played a protective role in acute necrotizing pancreatitis induced by acute hepatic injury through inhibition of inflammation and apoptosis that involved JNK and p38 MAPK-dependent reactive oxygen species. In the present study, we found that HRS significantly decreased expression of pro-inflammatory cytokines IL-1 $\beta$, IL- 6 , and TNF- $\alpha$ in the rat brain and decreased expression of apoptotic proteins. Thus, protective effects of HRS against CPB-induced brain injury are achieved through anti-inflammatory and anti-apoptotic pathways.

Previous studies have demonstrated that the PI3K/Akt/GSK3 $\beta$ signaling pathway is involved in apoptosis of neuronal cells during cerebral ischemia. Lu et al. [18]aimed to elucidate a possible mechanism underlying the neuroprotective effect of minocycline by using LY294002 to inhibit the PI3K pathway. Immunoblotting revealed that minocycline enhanced phosphorylation/activation of Akt and phosphorylation/inactivation of GSK3 $\beta$. The results suggest that the PI3K/Akt/GSK3 $\beta$ pathway is involved in the neuroprotective effect. Our results show that expression levels of of Bax and caspase- 3 were significantly higher in the CPB group, which suggests that CPB might induce neuronal apoptosis in the rat brain. Furthermore, in CPB rats, expression of Akt and GSK3 $\beta$ protein significantly increased compared with the control group, and expression of Akt and GSK3 $\beta$ significantly decreased after treatment with HRS. The results suggest that HRS protects brain neurons against CPBinduced injury by activating the PI3K/Akt/GSK3 $\beta$ pathway.

CMECs, which are one of the main components of neurovascular units, contribute to formation of the BBB, participate in the body's metabolism and endocrine synthesis, and synthesize and release dozens of bioactive substances [19]. In addition, these cells play an important role in regulating and maintaining stability and balance of the neurovascular microenvironment in the brain. Studies have shown that CMECs can directly affect function of neurons and synapses, BBB permeability, and abnormal expression of vascular receptors by altering cerebral blood flow through expression of vasoactive substances [20]. Furthermore, when vascular injury occurs, nerve cells, astrocytes, and microglia respond to activation by secreting several pro-inflammatory cytokines [21], thereby stimulating nerve injury, causing synaptic dysfunction, and triggering diseases. CMECs can directly or indirectly affect function of neurons and synapses and are involved in many neurological diseases, including cognitive impairment. Bader et al. [22] used CMECs to characterize the physiological link between adenosine receptors and gap junction coupling in endothelial cells of the BBB. The report identifies CNG channels as a physiological link that integrates gap junction coupling and adenosine receptor-dependent signaling of endothelial cells of the BBB. In this study, CMECs were subjected to conditions that simulated hypoxia and ischemia induced by CPB. Results showed that HRS inhibited neuronal apoptosis induced by hypoxia and ischemia. However, after LY294002 treatment, the protective effect was blocked, and expression levels of Akt, GSK3 $\beta$, P-Akt, and P-GSK3 $\beta$ were downregulated. Thus, inhibiting the PI3K/Akt/ GSK3 $\beta$ pathway reduced the protective effect on neurons. The PI3K/Akt/GSK3 $\beta$ pathway plays an important role in regulating function of cerebral blood vessels. Inhibiting the PI3K/ Akt/GSK3 $\beta$ pathway may aggravate neuronal injury, and HRS protects neurons from damage through the PI3K/Akt/GSK3 $\beta$ pathway.

In summary, the PI3K/Akt/GSK3 $\beta$ signaling pathway plays an important role in the mechanism of CPB-induced brain injury. HRS can alleviate CPB-induced brain injury, inhibit apoptosis of CMECs, and prevent brain injury through the PI3K/Akt/GSK3 $\beta$ signaling pathway. 


\section{Cellular Physiology Cell Physiol Biochem 2017;43:1634-1647 \begin{tabular}{ll|l} 
DOI: 10.1159/000484024 & $\begin{array}{l}\text { O 2017 The Author(s). Published by S. Karger AG, Basel } \\
\text { www.karger.com/cpb }\end{array}$
\end{tabular} \\ Chen et al.: HRS Protect Against Rat Brain Injury by PI3K/Akt/GSK3 $\beta$ Pathway During CPB}

\section{Acknowledgements}

This study was supported by the Natural Science Foundation of China (grant nos. 81471121 and 3120175), the New Teacher Foundation of China Medical University (XZR20160036), and the Liaoning Natural Fund Project (2015020404).

\section{Disclosure Statement}

The authors declare that they have no competing interests regarding the publication of this article.

\section{References}

1 Allyn J, Allou N, Augustin P, Philip I, Martinet O, Belghiti M, Provenchere S, Montravers P, Ferdynus C: A Comparison of a Machine Learning Model with EuroSCORE II in Predicting Mortality after Elective Cardiac Surgery: A Decision Curve Analysis. PLoS One 2017;12:e0169772.

2 Salameh A, Dhein S, Dahnert I, Klein N: Neuroprotective Strategies during Cardiac Surgery with Cardiopulmonary Bypass. Int J Mol Sci 2016;17:

-3 Lomivorotov VV, Shmyrev VA, Ponomarev DN, Efremov SM, Shilova AN, Postnov VG: [Influence of remote ischemic preconditioning on brain injury markers dynamics during cardiopulmonary bypass]. Anesteziol Reanimatol 2015;60:33-38.

-4 Blue ME, Wilson MA, Beaty CA, George TJ, Arnaoutakis GJ, Haggerty KA, Jones M, Brawn J, Manmohan S, Lange MS, Johnston MV, Baumgartner WA, Troncoso JC: Brain injury in canine models of cardiac surgery. J Neuropathol Exp Neurol 2014;73:1134-1143.

5 Li H, Wang B, Zhu C, Feng Y, Wang S, Shahzad M, Hu C, Mo M, Du F, Yu X: 17beta-estradiol impedes Bax-involved mitochondrial apoptosis of retinal nerve cells induced by oxidative damage via the phosphatidylinositol 3-kinase/Akt signal pathway. J Mol Neurosci 2013;50:482-493.

6 Yu H, Zhang H, Zhao W, Guo L, Li X, Li Y, Zhang X, Sun Y: Gypenoside Protects against Myocardial IschemiaReperfusion Injury by Inhibiting Cardiomyocytes Apoptosis via Inhibition of CHOP Pathway and Activation of PI3K/Akt Pathway In vivo and In vitro. Cell Physiol Biochem 2016;39:123-136.

7 Teng L, Meng Q Lu J, Xie J, Wang Z, Liu Y, Wang D: Liquiritin modulates ERK and AKT/GSK3betadependent pathways to protect against glutamateinduced cell damage in differentiated PC12 cells. Mol Med Rep 2014;10:818-824.

8 Shen M, Zhang H, Yu C, Wang F, Sun X: A review of experimental studies of hydrogen as a new therapeutic agent in emergency and critical care medicine. Med Gas Res 2014;4:17.

-9 Shigeta T, Sakamoto S, Li XK, Cai S, Liu C, Kurokawa R, Nakazawa A, Kasahara M, Uemoto S: Luminal injection of hydrogen-rich solution attenuates intestinal ischemia-reperfusion injury in rats.

Transplantation 2015;99:500-507.

10 Sun Q, Cai J, Zhou J, Tao H, Zhang JH, Zhang W, Sun XJ: Hydrogen-rich saline reduces delayed neurologic sequelae in experimental carbon monoxide toxicity. Crit Care Med 2011;39:765-769.

-11 Cao HJ, Sun YJ, Zhang TZ, Zhou J, Diao YG: Penehyclidine hydrochloride attenuates the cerebral injury in a rat model of cardiopulmonary bypass. Can J Physiol Pharmacol 2013;91:521-527.

$\checkmark 12$ Longa EZ, Weinstein PR, Carlson S, Cummins R: Reversible middle cerebral artery occlusion without craniectomy in rats. Stroke 1989;20:84-91.

13 Zhao S, Mei K, Qian L, Yang Y, Liu W, Huang Y, Zhang C, Sun X, Liu C, Li B, Gao F, Cai J, Ni J: Therapeutic effects of hydrogen-rich solution on aplastic anemia in vivo. Cell Physiol Biochem 2013;32:549-560.

14 Qian L, Shen J, Chuai Y, Cai J: Hydrogen as a new class of radioprotective agent. Int J Biol Sci 2013;9:887894.

15 Li J, Hong Z, Liu H, Zhou J, Cui L, Yuan S, Chu X, Yu P: Hydrogen-Rich Saline Promotes the Recovery of Renal Function after Ischemia/Reperfusion Injury in Rats via Anti-apoptosis and Anti-inflammation. Front Pharmacol 2016;7:106. 


\section{Cellular Physiology Cell Physiol Biochem 2017;43:1634-1647 \\ \begin{tabular}{ll|l} 
DOI: 10.1159/000484024 & $\begin{array}{l}\text { O 2017 The Author(s). Published by S. Karger AG, Basel } \\
\text { www.karger.com/cpb }\end{array}$ \\
\hline
\end{tabular} \\ Chen et al.: HRS Protect Against Rat Brain Injury by PI3K/Akt/GSK3 $\beta$ Pathway During CPB}

16 Gokalp N, Basaklar AC, Sonmez K, Turkyilmaz Z, Karabulut R, Poyraz A, Gulbahar O: Protective effect of hydrogen rich saline solution on experimental ovarian ischemia reperfusion model in rats. J Pediatr Surg 2017;52:492-497.

17 Shi Q Chen C, Deng WH, Wang P, Zuo T, Zhao L, Yu J, Zhao KL, Mei FC, Li C, Wang GR, Wang WX: HydrogenRich Saline Attenuates Acute Hepatic Injury in Acute Necrotizing Pancreatitis by Inhibiting Inflammation and Apoptosis, Involving JNK and p38 Mitogen-Activated Protein Kinase-dependent Reactive Oxygen Species. Pancreas 2016;45:1424-1431.

18 Lu Y, Lei S, Wang N, Lu P, Li W, Zheng J, Giri PK, Lu H, Chen X, Zuo Z, Liu Y, Zhang P: Protective Effect of Minocycline Against Ketamine-Induced Injury in Neural Stem Cell: Involvement of PI3K/Akt and Gsk-3 Beta Pathway. Front Mol Neurosci 2016;9:135.

19 Brailoiu E, Shipsky MM, Yan G, Abood ME, Brailoiu GC: Mechanisms of modulation of brain microvascular endothelial cells function by thrombin. Brain Res 2017;1657:167-175.

20 Zlokovic BV: Neurovascular mechanisms of Alzheimer's neurodegeneration. Trends Neurosci 2005;28:202208.

21 Man S, Ubogu EE, Ransohoff RM: Inflammatory cell migration into the central nervous system: a few new twists on an old tale. Brain Pathol 2007;17:243-250.

-22 Bader A, Bintig W, Begandt D, Klett A, Siller IG, Gregor C, Schaarschmidt F, Weksler B, Romero I, Couraud PO, Hell SW, Ngezahayo A: Adenosine receptors regulate gap junction coupling of the human cerebral microvascular endothelial cells hCMEC/D3 by Ca2+ influx through cyclic nucleotide-gated channels. J Physiol 2017;595:2497-2517. 